\title{
Philometra floridensis (Nematoda: Philometridae) damages ovarian tissue without reducing host (Sciaenops ocellatus) fecundity
}

\author{
Micah D. Bakenhaster ${ }^{1, *}$, Susan Lowerre-Barbieri ${ }^{1}$, Yasunari Kiryu ${ }^{1}$, Sarah Walters $^{1}$, \\ Emma J. Fajer-Avila²
}

\footnotetext{
${ }^{1}$ Florida Fish and Wildlife Conservation Commission, Fish and Wildlife Research Institute, Florida 33701, USA

${ }^{2}$ Centro de Investigación en Alimentación y Desarrollo, A.C., Unidad Mazatlán en Acuicultura y Manejo Ambiental, CP 82010 Mazatlán Sinaloa, Mexico
}

\begin{abstract}
The parasitic nematode Philometra floridensis infects the ovary of its only host, the economically important fish species Sciaenops ocellatus, but the factors influencing host susceptibility and potential pathogenic effects are unknown. Here we report new information on these topics from evaluations of infected and uninfected hosts collected from the northeastern Gulf of Mexico. Fish length and age were evaluated vis-à-vis nematode prevalence to check for ontogenetic differences in host susceptibility. To evaluate health and reproductive consequences of infection, we looked for effects in Fulton's condition factor $(K)$ and batch fecundity estimates (BF), and we evaluated ovarian tissue histologically to check for oocyte atresia and other host responses. We observed localized pathological changes in fish ovarian tissue associated with female nematodes, including leucocytic exudates, granulomatous inflammation, and Langhans-type multinucleated giant cells; the hosts, however, appeared to maintain high fecundity and actually exhibited, on average, better health index scores and higher relative fecundity than did uninfected fish. These differences are likely explained by the parasite's tendency to disproportionately infect the largest, actively spawning fish and by the localization of pathogenic changes, which could have masked effects that otherwise would have been reflected in mass-based health indicators. Although we did not detect negative effects on measures of overall health or reproductive output, further research is needed to better elucidate the relationship between these parasites and other factors affecting host reproductive potential, such as egg quality.
\end{abstract}

KEY WORDS: Red drum - Granulomatous inflammation · Multinucleate giant cells · Batch fecundity $\cdot$ Condition factor $\cdot$ Gonadosomatic index

\section{INTRODUCTION}

Gonad-infecting parasitic nematodes of the family Philometridae have been reported to cause significant damage to the gonads of wild and cultured marine perciform hosts with varying consequences including severe reduction in reproductive fitness based on gross and histological pathology (Ramachandran 1975, Hine \& Anderson 1981, Sakaguchi et al. 1987,

\footnotetext{
*Corresponding author: micah.bakenhaster@myfwc.com
}

Oliva et al. 1992, Hesp et al. 2002, Clarke et al. 2006, Moravec 2006, Perez et al. 2009, Chávez \& Oliva 2011). Reports of reproductive effects utilizing direct quantifiable measures acceptable to fisheries biologists are generally wanting for this group (Moravec \& de Buron 2013), and there is no specific information on health or reproductive effects of Philometra floridensis (Nematoda: Philometridae) on red drum Sciaenops ocellatus (Perciformes: Sciaenidae).

(C) The authors 2014. Open Access under Creative Commons by Attribution Licence. Use, distribution and reproduction are unrestricted. Authors and original publication must be credited. 
The red drum is an economically important sport and food fish, and is the only reported host for the ovarian parasite Philometra floridensis. The US National Oceanic and Atmospheric Administration (NOAA) estimated that Florida anglers harvested $1.2 \times 10^{6} \mathrm{~kg}$ of red drum in 2012 (NOAA, Marine Fisheries Statistics, pers. comm. 2013). In Florida, concerns about depleted stocks have led to strict fisheries regulations including bag limits, minimum and maximum size limits for recreational/subsistence anglers, and a 2-decade prohibition of commercial harvest (Murphy \& Munyandorero 2009). The US states of Florida, South Carolina, and Texas have government-funded aquaculture programs aimed at stock enhancement of this species (Leber 2004), and it is cultured as a food fish in Martinique, Ecuador, Israel, and China (FAO 2013).

The reported prevalence of Philometra floridensis in wild stocks of red drum (as much as $93 \%$ of female hosts infected; Moravec \& de Buron 2009) and its broad geographic range suggest that any detrimental health or reproductive consequences of infection could manifest on a large scale. The host occurs in the western Atlantic and Gulf of Mexico from Massachusetts in the USA to northern Mexico (Froese \& Pauly 2013), and likely so does the parasite. Overstreet (1978) reported a philometrid (almost certainly P. floridensis, R. M. Overstreet pers. comm.) infecting red drum ovaries in the north-central Gulf of Mexico (west of Mobile Bay), so in all likelihood it ranges in the Gulf at least to Texas. In the northwest Atlantic, the distinct bioregional break at Cape Hatteras (i.e. the border between the Carolinian and Virginian subprovinces; see Cook \& Auster 2007) might present some barrier, but Moravec \& de Buron (2009) collected infected hosts only $400 \mathrm{~km}$ down the US Eastern Seaboard in Winyah Bay, South Carolina.

Infections have been reported only from mature female hosts during or near their active spawning season (Moravec \& de Buron 2009, Moravec et al. 2010). Red drum are asynchronous, multiple-batch spawners (Wilson \& Nieland 1994), with males reaching maturity at 1 to $3 \mathrm{yr}$ of age and from 350 to $799 \mathrm{~mm}$ fork length, and females at 3 to $6 \mathrm{yr}$ of age and from 550 to $899 \mathrm{~mm}$ fork length. Spawning occurs in late summer and early fall from August through November (Murphy \& Taylor 1990). In Florida, adults occur primarily in fully marine, nearshore, shelf waters (Murphy \& Munyandorero 2009). Juveniles are physically and ecologically separated from adults and occur in upper estuarine habitats such as rivers, tidal creeks, bays, and canals (Peters \& McMichael 1987).
The particulars of the relationship between Philometra floridensis and red drum, such as when and how fish become infected, are unknown but could have bearing on whether measures should be taken to exclude the parasite from aquaculture facilities or on decisions about geographic placement of sea cages. Apparently, P. floridensis infects captive, adult red drum at The Florida Fish and Wildlife Conservation Commission (FWC) Stock Enhancement Research Facility (SERF) near the mouth of Tampa Bay. At this facility, wild-caught brood fish are maintained in earthen ponds with raw water drawn from Port Manatee. They are moved to indoor tanks for spawning, and fertilized eggs are isolated from tank water. In November 2012, nematode larvae morphologically consistent with those of $P$. floridensis were present among a sample of isolated eggs (M. D. Bakenhaster pers. obs.). Since the most recent capture date for a female fish in this spawning event was fall of 2010, either infections persist in hosts for extended periods or the fish are vulnerable to reinfection under these culture conditions. For the few philometrid species whose life cycles are known, the parasites require an intermediate arthropod host (typically a copepod) and are ultimately ingested by the definitive host whether or not a paratenic host is involved (Moravec 2006, Moravec \& de Buron 2013). No paratenic or intermediate hosts have been identified for $P$. floridensis, nor is there any information about when red drum become ecologically susceptible to infection in the wild.

This study was conducted to identify health or reproductive consequences of parasitism for hosts, and to gather preliminary data on ecological aspects of the host-parasite relationship. Gross and histological appearance of the parasite is described. We used histopathological analyses, health indices, histological staging of red drum ovaries, and batch fecundity estimates to check for effects of the parasite on its host. We evaluated prevalence of infection with respect to host size, age, and reproductive stage to identify links between host and parasite life history.

\section{MATERIALS AND METHODS}

Red drum were collected during 2 sampling events ( 2 and 7 October 2008) from waters off Tampa Bay as part of a population-assessment study conducted by the Florida Fish and Wildlife Conservation Commission-Fish and Wildlife Research Institute (FWCFWRI). A commercial spotter plane and a purse seine 
vessel were hired to locate and capture schooling red drum in nearshore Gulf of Mexico waters during the fish's spawning season. For each school seined, approximately 150 fish were asystematically selected and removed, and the remaining fish were released. Fish were placed on ice overnight and transported to the FWC-FWRI, St. Petersburg laboratory for evaluation the following day. They were measured for total and standard lengths (TL and $\mathrm{SL}, \pm 1 \mathrm{~mm}$ ), total (wet) weight (TW, $\pm 1 \mathrm{~g})$, and gonad weight $(\mathrm{GW}, \pm 0.1 \mathrm{~g})$. Somatic weight (SW) was estimated as TW - GW. Both sagittal otoliths were removed and stored dry.

Ovaries were macroscopically examined for the presence of yolked oocytes, hydrated oocytes, and nematodes. Samples of ovarian tissue collected for histological staging and for estimates of batch fecundity (BF) were collected asystematically from either ovarian lobe except that in nematode-infected ovaries, we deliberately collected these samples from areas not proximate to obvious nematode bundles. We used histological techniques for (1) staging host ovaries and (2) cytological pathology. Tissues for these purposes were fixed in $10 \%$ neutrally buffered formalin or $5 \%$ paraformaldehyde, respectively. After a minimum of 24 hours' fixation, tissues were rinsed in water, dehydrated, and stored in $70 \%$ ethanol. Tissues were embedded in JB-4 glycol methacrylate resin (staging and pathology) or paraffin (pathology only). Resin-embedded tissues were stained with periodic acid-Schiff hematoxylin and counterstained with metanil yellow (PAS; staging) or hematoxylin and eosin (H\&E; pathology). Paraffinembedded tissues were stained with H\&E or thionin (pathology). Photomicrographs were prepared and measurements were made with an Olympus BX51 microscope equipped with an Olympus DP71 digital camera.

Oocyte developmental stages were assigned following Wallace \& Selman (1981) and LowerreBarbieri et al. (2011). We identified stages of atresia of vitellogenic oocytes according to the criteria defined by Hunter \& Macewicz (1985). The first identifiable characteristic of alpha atresia was considered to be degeneration of the chorion or zona pellucida. The intensity of atresia within each ovary was categorized as (1) none; (2) intermediate $(<50 \%$ of vitellogenic oocytes undergoing atresia); or (3) widespread $(>50 \%)$, associated with regressing ovaries, which are no longer capable of spawning in the near future (Brown-Peterson et al. 2011).

We estimated BF gravimetrically using the hydratedoocyte method (Hunter et al. 1985) for ovaries macroscopically identified as having hydrated oocytes.
Fresh oocytes were hydraulically separated from each other and from the ovarian membrane and preserved in $2 \%$ neutrally buffered formalin according to the methods of Lowerre-Barbieri \& Barbieri (1993). To reduce bias due to oocyte settlement rates, we stirred samples before removing 2 subsamples (ca. $0.1 \mathrm{~g}$ ). All hydrated oocytes were counted in these subsamples. If histological analysis indicated that ovulation had begun, the BF estimate was not used.

In a subsample of 31 infected female fish from the second sampling event, the lobe of the ovary not sampled for histological staging and BF was saved for parasitological evaluation and excision of tissue for histopathology. For 19 of these specimens (selected asystematically), we weighed the single gonad lobe $( \pm 0.1 \mathrm{~g})$ to estimate the relative masses of parasites and ovarian tissue. From these samples, whole nematodes were extracted for description (see Moravec et al. 2010) and enumeration. Thus, while presence and absence of infection was determined from observation of both ovaries, nematodes were counted from only 1 lobe, which was selected asystematically from the pair. Therefore, we did not necessarily obtain true intensity data, so we defined an intensity proxy variable, NemIN (NemIN = number of female nematodes in a single ovarian lobe). Males of Philometra floridensis were minute, easily overlooked, and presumably of little health consequence compared with females, so males were not considered for NemIN. In scoring for presence or absence of nematodes, we counted ovaries with encapsulated, dead nematodes as positive for infection; however, dead parasites were not considered in measurements of NemIN. We could not practically unravel all nematode bundles, so we counted protruding anterior and posterior ends of female nematodes to determine NemIN (after Hesp et al. 2002).

Fish were aged using transverse sections of sagittal otoliths (Murphy \& Taylor 1990). Otoliths were sectioned through the core using a Buehler low-speed Isomet saw. Sections, 350 to $500 \mu \mathrm{m}$ thick, were mounted on glass slides with Thermo Shandon FloTexx. The number of annuli and the distance from the edge of the otolith to the most recent annulus were determined by viewing the sections with transmitted light under a dissecting microscope. Sections that were difficult to read were also viewed in reflected light. All slides were read twice by 2 readers. Discrepancies were resolved by the primary reader. To assign age, we assumed a biologically realistic hatch date of 1 October, and ages were incremented on this date. 


\section{Data analysis}

As the fish were captured in the same week and the same area, samples taken on the 2 dates were combined for data analyses. Parasite prevalence was evaluated for both sexes, and because no parasites were found in testes, only female hosts were used for further analyses. All statistical analyses were performed using SAS version 9.2 (SAS Institute 2006) and an alpha level of 0.05 .

Because $K$ (Fulton's condition factor) is a good indicator of general condition in terms of protein and lipid (Lambert \& Dutil 1997), we used this as a measure of overall health and past feeding. It was calculated as $K=\left(\mathrm{SW} / \mathrm{TL}^{3}\right) \times 10^{5}$, and means were compared with a $t$-test.

To assess whether parasites, size, condition, or age significantly affected $\mathrm{BF}$, step-wise linear regression was used to model the relationship between BF and the following main effects: parasites, SW, $K$, and age.

To test whether fish of all sizes and ages were equally likely to be infected, the mean size and mean age of fish with and without parasites were compared with a nonparametric Mann-Whitney test. To evaluate whether size or age affected prevalence, the proportion of fish with parasites was modeled using generalized linear models (PROC GENMOD in SAS), a binomial distribution, and a logit link function. To meet model criteria, ages were binned in groups of 3 , except the oldest ages, which were binned to include ages 21 to 24 . Lengths were grouped by $50 \mathrm{~mm}$ bins, with the exception of the smallest bin, which included all fish of $<850 \mathrm{~mm}$ TL. Size classes were demarcated at intervals of $50 \mathrm{~mm}$ TL.

\section{RESULTS}

\section{Prevalence and intensity}

We evaluated 290 red drum (164 males, 0 infected; 126 females, 58 infected). The average age was $12 \mathrm{yr}$ for both sexes, but the age range of males was larger ( 3 to $29 \mathrm{yr}$ ) than that of females ( 3 to $24 \mathrm{yr}$ ). From the 124 females histologically assessed, all but 3 were mature and the majority $(\mathrm{n}=113 ; 91 \%)$ were undergoing oocyte maturation and would have spawned on the night of the collection date. Female fish ranged in size from 728 to $1051 \mathrm{~mm}$ TL, and parasitized females were larger and older, on average, than unparasitized females. Parasitized fish had a mean TL of $943 \mathrm{~mm}$ and a mean age of $12.8 \mathrm{yr}$, compared with $912 \mathrm{~mm}$ TL and $10.6 \mathrm{yr}$ for unparasitized fish, and these differences were significant (TL, Mann-Whitney, $\mathrm{n}=126, \mathrm{p}=0.0075$; age, MannWhitney, $\mathrm{n}=126, \mathrm{p}=0.0208$ ). The proportion of infected fish increased significantly with length class $\left(\chi^{2}=10.51, \mathrm{df}=4, \mathrm{p}=0.0326\right)$ but not with age class $\left(\chi^{2}=11.11\right.$, df $\left.=6, \mathrm{p}=0.085\right)$.

We found no trends in the intensity of the infection (NemIN) with respect to size or GW. We observed a range in NemIN of 1 to 7 parasites (mean $=4$ ). The NemIN value was not correlated to fish TL $\left(\mathrm{R}^{2}=\right.$ 0.133, $\mathrm{n}=12, \mathrm{p}=0.24), \mathrm{SW}\left(\mathrm{R}^{2}=0.0873, \mathrm{n}=11, \mathrm{p}=\right.$ $0.673)$, or GW ( $\left.R^{2}=0.0176, n=12, p=0.681\right)$.

\section{General, gross and histological characteristics of infection}

Female nematodes were dark red and occurred primarily in tightly entwined bundles of 1 to 4 individuals (Fig. 1A); multiple bundles were sometimes present in a single lobe (Fig. 1B), and both lobes of some fish were infected. These bundles were often readily observed through the ovarian wall; they appeared as dark patches in otherwise pinkish ovarian tissue (Fig. 1C). Bundled nematodes collectively constricted and perforated ovarian lamellae and supporting connective tissue, effectively anchoring the parasites within the ovary. Only pre-ovigerous female nematodes were observed to occur unbundled in a relatively relaxed condition. Dead, encapsulated nematodes were often observed in ovaries with living nematodes. These presented grossly as dark brownish to black masses (Fig. 1D), sometimes with recognizable portions of protruding female nematodes.

The tubular shape of living female nematodes was not always evident in histological section, because once their body walls were ruptured, they became flaccid, and artifact spaces occurred between parasite and host tissue; still, the basic structure was apparent and consisted of a relatively thin body wall (cuticle, hypodermis, and muscle sheets) surrounding a sac-like uterus and intestine (Fig. 2A). Uteri were occasionally empty but more commonly contained broods of embryos, larvae, or a combination of both. Small, PAS-positive nematodes were occasionally observed free in the host's ovarian lumen and, in one instance, occupying the lumen of a blood vessel in the mesovarian mesentery. The cuticle was uniform and smooth in most sections and lacked annuli; although, sometimes it was deeply furrowed. Lateral hypodermal cords were very long transversely to the extent that they were better characterized as hypo- 

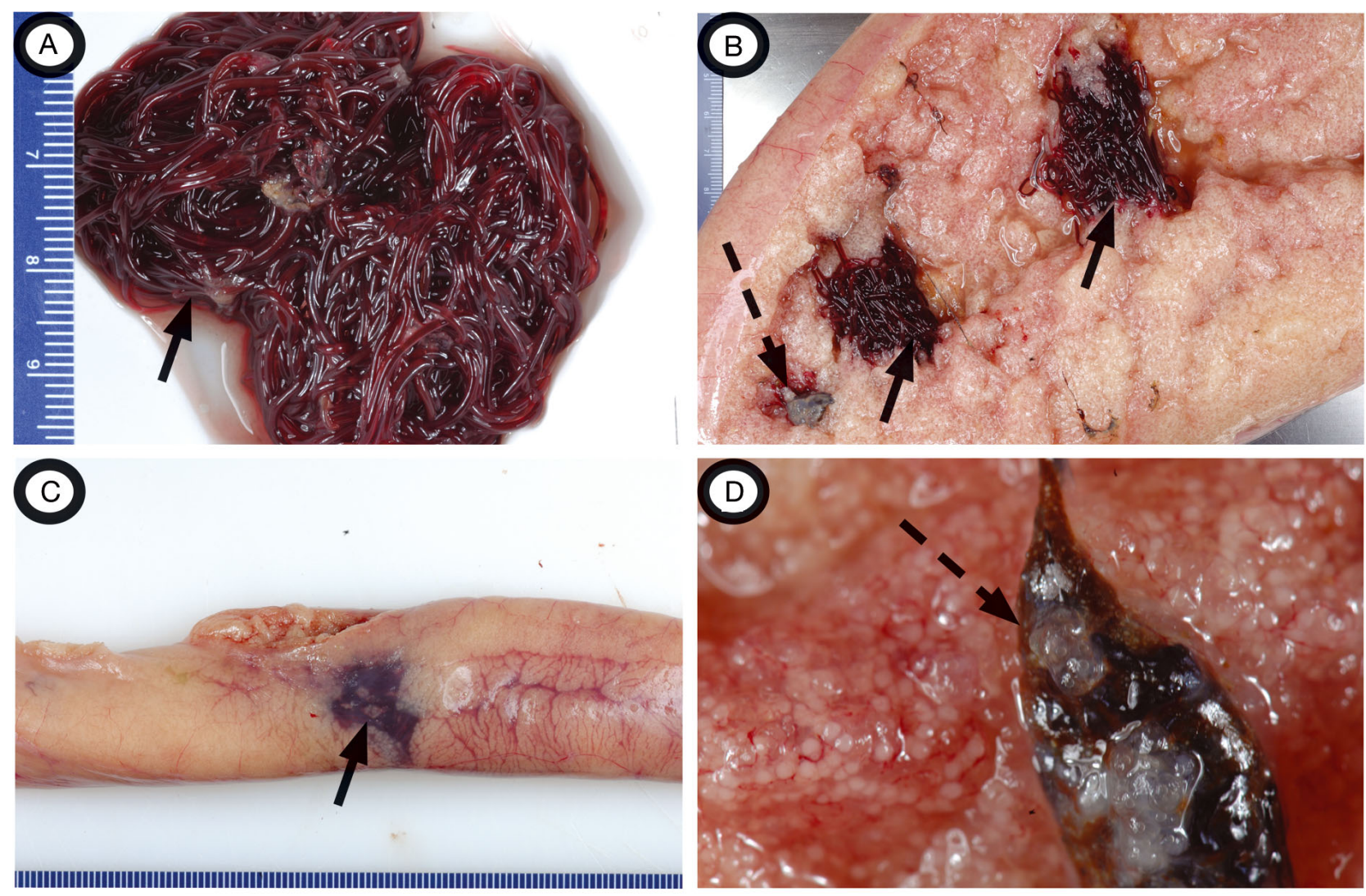

Fig. 1. Philometra floridensis infecting ovaries of Sciaenops ocellatus. Solid arrows indicate live nematodes, broken arrows indicate dead nematodes encapsulated by the host, and tick marks on blue rulers represent mm. (A) Bundle of female specimens of $P$. floridensis removed from ovary; (B) ovary slit along its length to show nematodes in situ; (C) external appearance of infected ovary with visible nematode bundle and apparently associated congested or hemorrhagic ovarian tissue; (D) granulomatous host response (encapsulation) to dead nematode(s)

dermal bands. Thus, large portions of the body wall were devoid of muscle cells. The body wall was thickest at the median cords (Fig. 2B), about $75 \%$ thicker than at lateral bands (mean 57 vs. $14 \mu \mathrm{m}$ thick in 5 measured sections selected asystematically). Muscle cells were polymyarian in arrangement, shallow-coelomyarian in shape, and gradually decreased in size with distance from medial hypodermal cords until the muscle sheets ended abruptly at the lateral hypodermal bands (Fig. 2C). The sarcoplasmic portions of muscle cells were basophilic and PAS positive, and muscle spindles were eosinophilic and PAS negative (Fig. 2B,C). Nematode intestines were typically filled with pooled host erythrocytes, demonstrating hematophagy.

Ovarian tissue from uninfected fish was not histologically different from tissue of infected fish collected from regions distant from nematode bundles, but severe pathological changes were observed in tissue immediately associated with parasites. The extent of the host response was directly related to proximity to nematode bundles and appeared to be most severe around the largest masses, which contained the greatest numbers of individual nematodes. Bundled parasites elicited pathological changes, especially in the tissue they utilized for anchoring, but also in adjacent tissue.

In ovaries infected with living nematodes, lesions characteristically showed hemorrhage in the ovarian cavity and dramatic thickening of stromal connective tissue, which also had leucocytic infiltrations consisting primarily of macrophages, lymphocytes, eosinophilic granulocytes (EGCs), and some fibrocytes (Fig. 3A,B). Atretic oocytes occurred near nematodes, but also in healthy tissue as a normal part of the reproductive cycle (Fig. 3C). Leucocytic infiltrates were also present in ovarian tissue of uninfected fish and in unaffected areas of parasitized hosts, but to a much lesser degree than was observed near worm bundles. While intact oocytes were present in regions affected by parasites, their numbers were much smaller than in unaffected regions (Fig. 3D), 
although they were present in other areas of affected ovaries including those adjacent to encapsulated dead nematodes. Mesovarian mesentery peripheral to nematode bundles was infiltrated with EGCs and showed sporadic areas of edematous fluid (grayish under H\&E stain). In some cases, oocytes in proximity to the parasites were necrotic (although we did not attempt to distinguish this condition from atresia that is typical in teleosts after spawning), and, rarely, Langhans-type and foreign body-type multinucleate giant cells were observed engulfing lysed oocyte material.

Dead or dying nematodes were engulfed by massive granulomatous inflammation (granuloma). Granulomas comprised 3 layers (Fig. 3E): (1) an innermost layer consisting of multiple foci of necrotized nematode tissue, which contained lysed eosinophilic materials (PAS positive), calcified material, melanin, and cholesterol clefts. These foci were surrounded by a proteinaceous matrix infiltrated prominently with EGCs, lymphocytes, and macrophage aggregates; (2) a middle layer of epithelioid cells arranged into several sublayers; and (3) an outermost enveloping layer

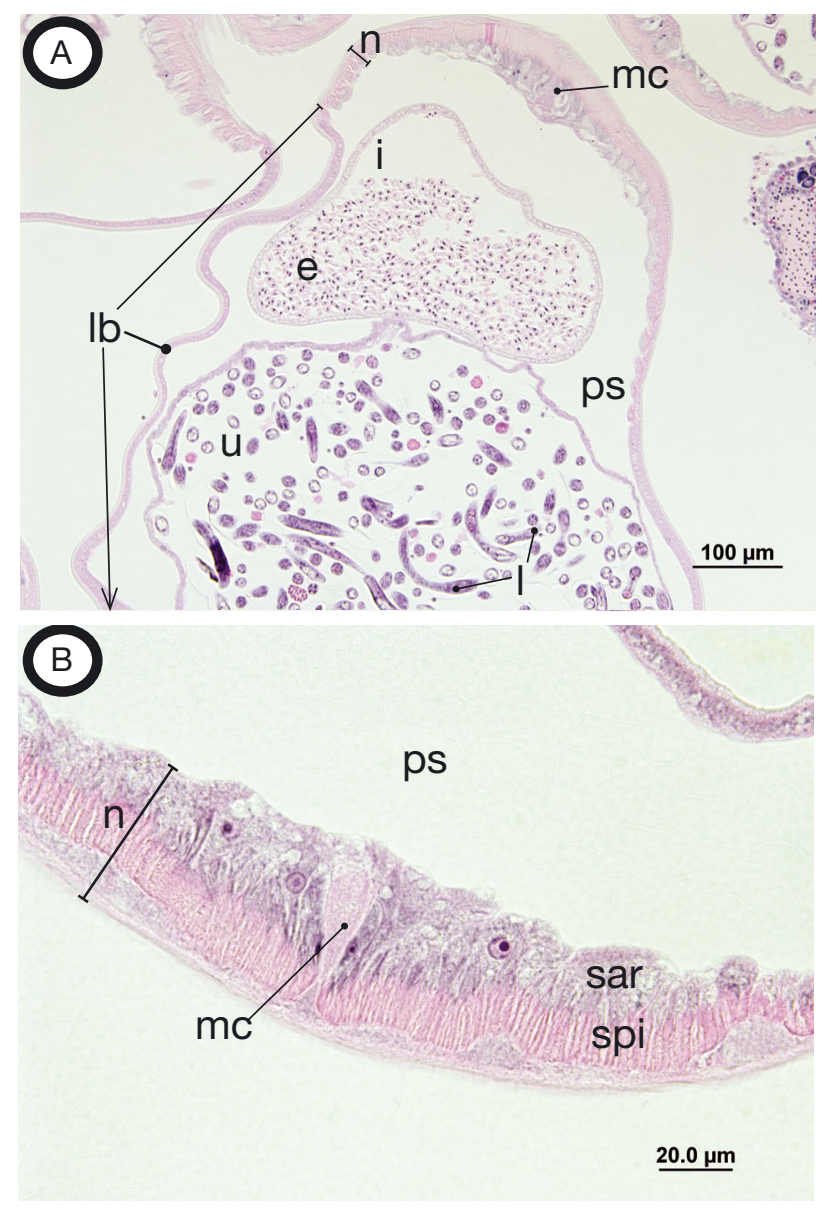

consisting of EGCs, fibrocytes, necrotic debris, newly constructed congested capillaries, and notably large Langhans-type multinucleated giant cells. Multinucleated giant cells (Fig. 3F) in the outermost layer were observed to engulf the presumed remains of necrotized nematodes, which presented as elongate ovoid cavities with homogenous eosinophilic (and PASnegative) centers. In the innermost layer, necrotic foci contained colonies of short, rod-shaped bacteria in their center and along their outer margin. These bacteria were readily observed in thionin-stained sections.

\section{Impacts on health and reproductive potential}

Health indices did not show detrimental effects of infection by nematodes. Parasitized fish had a mean $K$ of 0.97 . This was slightly higher than $K$ in uninfected fish (0.95), but these differences were not significant ( $t$-test, $\mathrm{n}=126, \mathrm{p}=0.1055)$. Analysis of ovarian reproductive stage indicated that parasites also did not decrease net reproductive output by interfering with oocyte developmental progression in the

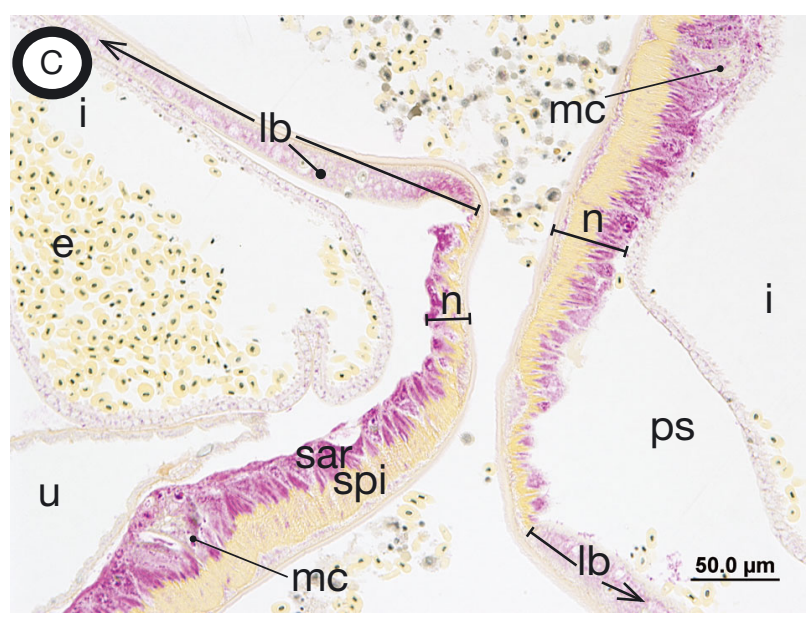

Fig. 2. Philometra floridensis infecting ovaries of Sciaenops ocellatus. (A) Hematoxylin and eosin (H\&E)-stained cross section through larvigerous nematode with intestine full of host erythrocytes; (B) H\&E-stained cross section through median hypodermal cord showing sarcoplasmic (basophilic) and spindle (eosinophilic) portions of muscle cells; (C) periodic acid-Schiff hematoxylin (PAS)-stained cross section of 2 nematodes showing muscle sheets, which have both sarcoplasmic (PAS-positive) and spindle (PAS-negative) portions of muscle cells that taper in size until ending abruptly at the lateral hypodermal nerve bands. e: host erythrocytes; i: intestinal lumen; l: nematode larvae; lb: lateral hypodermal band (homologous to lateral cord); mc: median hypodermal cord; n: nematode body wall; ps: nematode pseudocoel; sar: sarcoplasmic portion of muscle celli spi: spindle portion of muscle cell; u: uterine lumen 


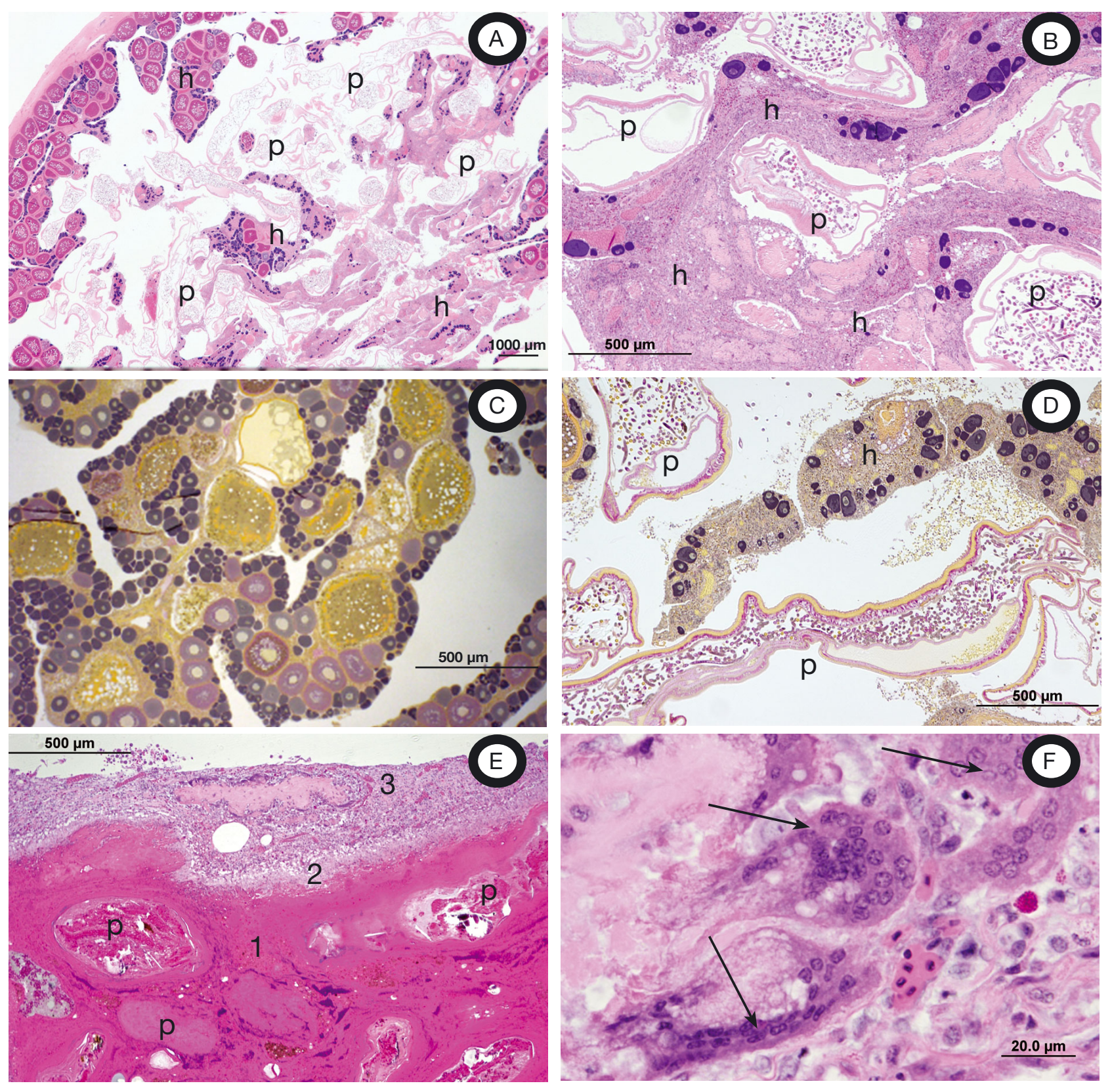

Fig. 3. Philometra floridensis infecting ovaries of Sciaenops ocellatus. Sectioned ovaries showing both healthy tissue and severe host response in infected tissue (p: parasite tissue, h: host tissue). (A) Coils of bundled nematodes surround masses of severely damaged host tissue (hematoxylin and eosin, H\&E); (B) infected tissue showing leucocytic infiltrates and dramatic pathological alteration of the overall structure of ovarian tissue (H\&E); (C) an example of a non-infected female with massive atresia of vitellogenic oocytes (periodic acid-Schiff, PAS); (D) affected ovarian tissue typical of areas adjacent to nematode bundles showing dramatic thickening of stromal tissue with leucocytic infiltrates and relatively few oocytes, none of which is mature (PAS); (E) granulomatous encapsulation around dead nematode bundle (p) showing 3 distinct layers: (1) foci of necrotized nematode tissues surrounded by proteinaceous matrix, (2) epithelioid layer, and (3) enveloping outer layer (H\&E);

(F) Langhans-type giant cells (arrows) engulfing necrotized remains of nematodes in outermost layer of capsule (H\&E)

ovary as a whole (despite local effects mentioned above). Only 5 fish had atretic vitellogenic oocytes, and 3 of these exhibited massive atresia (stage 3 ), but only 1 of these 3 was infected. This early resorption of yolked oocytes may have been related to the relatively young age of these fish ( 2 age 5, 1 age 3 ). The 2 females that exhibited intermediate atresia (stage 2) were older (ages 8 and 17). 
We observed a range in BF of 95478 to 5.7 million eggs per female, and BF significantly increased with $\mathrm{SW}\left(\mathrm{BF}=-372.030+400.0 \mathrm{SW} ; \mathrm{R}^{2}=0.36, \mathrm{n}=110\right)$. The predictive BF relationship with SW was marginally improved by including presence of parasites $\left(\mathrm{R}^{2}=0.38, \mathrm{p}=0.0207\right)$ but not age or $K$. Infected fish exhibited marginally higher BF than uninfected fish.

\section{DISCUSSION}

\section{Prevalence and intensity}

Based on macroscopic evaluation, Philometra floridensis apparently infects only mature female hosts, with the greatest prevalence occurring in the largest and oldest females. Our prevalence and intensity findings elucidate some connections between the life histories of $P$. floridensis and its host, connections that could be useful in predicting host susceptibility and health effects at the population level. Clearly, $P$. floridensis rarely, if ever, infects male hosts, which aggregate with females and presumably have similar exposure to infective larvae. Multiple lines of evidence suggest that the most fecund female red drum are the preferred hosts of $P$. floridensis. Prevalence was highest in the largest and oldest females, which are also the most fecund. Notably, macroscopically visible infections of $P$. floridensis appear to be very rare in red drum captured from estuarine waters of the Tampa Bay region, where younger fish are the dominant component of the red drum population (Murphy \& Munyandorero 2009). Of more than 1400 red drum collected by FWRI workers for health evaluations from estuarine waters in and around Tampa Bay since 1983, necropsy reports indicate only 2 cases of ovary-infecting nematodes (FWC-FWRI unpubl. data). The apparent presence of infections by $P$. floridensis in captive red drum brood stock at SERF underscores the potential for practical applicability of ecological data in this host-parasite relationship. An example of an epizootic, parasitic disease attributed to a species of Philometra in captive fish was given by Séguin et al. (2011), who reported high mortality rates associated with intense infections by $P$. rubra (reported as Philometra sp., see Moravec et al. 2013) of captive-reared fingerlings of striped bass Morone saxatilis. Although substantial lesions superficially similar to those described by Séguin et al. (2011) had been previously reported from infected wild striped bass in eastern North America (see Moravec 2006 and references therein), P. rubra, a natural body cavity parasite of $M$. saxatilis, may have become highly pathogenic only under culture conditions. Séguin et al. (2011) concluded that the intense infections they observed must have been obtained by the fish prior to their capture from the Miramichi River (New Brunswick, Canada) and they suggested that prophylactic treatment of newly captured stock or a captive breeding program could be an effective means to avoid this problem in the future. Fortunately, neither epizootics nor brood stock reproductive problems attributable to infections by $P$. floridensis have occurred at SERF since 1988, when red drum production began there. Nevertheless, the presence of the worms warrants consideration. Schools of spawning red drum, and presumably infected intermediate copepod hosts, are little, if at all, separated from the SERF water supply intake at Port Manatee.

Since it seems unlikely that wild adult red drum have age- or size-specific differences in exposure to infected prey, the greater prevalence of parasites in the oldest and most fecund fish evaluated for this study could be partly explained by the accumulation of parasites over time. However, infections carried by these hosts were neither more intense nor more pathogenic than in the younger cohort, as might be expected if infections are maintained for more than 1 spawning season. Further, if Philometra floridensis follows the same life history pattern reported for its sympatric congener, $P$. carolinensis (Perez et al. 2009), then macroscopically visible infections should occur only in reproductively mature hosts during their spawning season, and female worms should be encapsulated and killed by the host's immune system at the end of each season. This pattern has been demonstrated for some other Philometra species (Hesp et al. 2002, Clarke et al. 2006). Although infected adult hosts occur outside their peak spawning season in FWC-FWRI samples collected from the Indian River Lagoon on Florida's Atlantic Coast, in these cases, dead, encapsulated nematodes far outnumber live ones (M. D. Bakenhaster pers. obs.). Such an annual life cycle in sync with host spawning would seem to preclude accumulation of nematodes over time, unless latent, subclinical infections are maintained from year to year. Finally, females of Philometra spp. have blind-ended reproductive tracts and release larvae into the environment only through ruptures in their body walls (Moravec 2006), a dispersal strategy that is almost certainly fatal to the adult.

Intensity of infection likely has strong implications in the pathogenic potential of Philometra floridensis. Hesp et al. (2002) found that P. lateolabracis (likely a misidentification; see Quiazon et al. 2008) infecting 
the ovaries of Glaucosoma hebraicum did not have substantial health impact. They suggested that the volumetric and mass ratios of nematode and ovarian tissue could explain these differences. Within a given host-parasite relationship, this ratio may largely be determined by intensity, but when comparing the ratio among species, one must consider the relative size of individual female worms (e.g. females of $P$. lateolabracis [up to $230 \mathrm{~mm}$ ] can be markedly shorter than those of $P$. floridensis [up to about 1000 mm]; Moravec 2006, Moravec et al. 2010). Our intensity measurements were similar to those of Hesp et al. (2002; a maximum of 7 nematodes per host) and in contrast to those of Moravec et al. (1997), Clarke et al. (2006), and Chávez \& Oliva (2011) who reported extreme intensities of $84,>100$, and 99 nematodes per host in Epinephelus morio infected by P. margolisi, Pomatomus saltatrix infected by Philometra saltatrix and Genypterus chilensis infected by P. genipteri (reported as $P$. chilensis), respectively. In these latter cases, intense infections were associated with substantial concurrent pathological changes. The factors governing intensity have not been identified for P. floridensis, and infection intensity may range much higher than we have observed. Further, intensity (and prevalence) may vary greatly among years or locations, and the potential for heavy infections to develop in captive fish is unknown.

\section{General, gross and histological characteristics of infection}

Philometra floridensis is conspicuous in histological sections and also easily visible grossly because of its dark-red coloration and large size. Doubtless, the species has long been noticed by fishers and fisheries biologists, yet it remained undescribed for $31 \mathrm{yr}$ after Overstreet's (1978) report. This is probably a reflection of the logistic difficulties inherent in proper collection and description of philometrids (see Moravec 2006). The characteristic appearance of sectioned philometrids can sometimes allow for their detection by fisheries researchers during histological reproductive staging even when the parasites have not been detected grossly (e.g. see Jenkins \& McBride 2009), but these observations are probably seldom reported.

Our histomorphological findings for Philometra floridensis show that this species possesses the characteristics typical of its genus (Moravec 2006). We interpret the furrows present in some of our sectioned worms as most likely an artifact resulting from a ruptured body wall. Uteri without contents were likely another artifact of ruptured body walls, and indeed we sometimes observed that larvae and eggs were forcefully voided through tears in the cuticle of fresh specimens. Our observation that sarcoplasmic portions of muscle cells and the hypodermis of $P$. floridensis were PAS positive would be expected if they contain glycogen deposits as reported by Frantová et al. (2005) for P. obturans (vascular parasite of Esox lucius). Although not specifically illustrated, those authors also noted that $P$. obturans possessed a broad pair of lateral cords, containing the nuclei of the hypodermal syncytium. However, they described the musculature of $P$. obturans as being robust and they likened that worm's muscular physiology to that of Loa loa (parasite of multiple tissues of humans) as described by Franz et al. (1984). Females of L. loa possess muscle sheets that are circumferentially continuous except where they are briefly interrupted by relatively narrow and consolidated lateral cords, and also that muscle cells of $L$. loa occupy a much greater portion of its pseudocoel relative to those of $P$. floridensis (Franz et al. 1984, their Fig. 1). At least some other philometrid species, in common with Philometra floridensis, apparently have a relatively degenerative (highly derived) musculature and lateral hypodermal bands. For example, a superficially similar body wall can be discerned in P. cyprinirutili (abdominal cavity parasite of cyprinids; Lamah et al. 1990 [as P. ovata], their Fig. 5f), P. carolinensis (ovarian parasite of Cynoscion nebulosus; Perez et al. 2009, their Fig. 9a), P. saltatrix (ovarian parasite of Pomatomus saltatrix; Clarke et al. 2006, their Fig. 5D), P. overstreeti (parasite of the mouth and branchial arches of Paralichthys lethostigma; De Buron \& Roumillat 2010, their Figs. 3 \& 4), and Nilonema gymnarchi (swimbladder parasite of Gymnarchus niloticus; Moravec 2006, his Fig. 89e). Other examples of spirurid nematodes shown to possess reduced musculature and band-like lateral hypodermal cords at midbody are Litomosoides carinii (pleural cavity parasite of the cotton rat; Franz \& Andrews 1986) and Onchocerca volvulus (subcutaneous parasite of humans; Franz \& Büttner 1983), and O. gibsoni (subcutaneous parasite of cattle; Franz et al. 1987). As suggested by Frantová et al. (2005), variability in musculature of adult female worms among philometrid species almost certainly results from an adaptation to the physical demands of their respective micro-habitats and behaviors.

Our histopathological findings are generally consistent with those described for other gonad-infecting philometrids by authors who have provided sufficient details for comparison, but there is a substantial 
range in the severity of reported effects (Table 1). Hine \& Anderson (1981) noted that severe infections of Pagrus auratus by Philometra sp. could result in the displacement or destruction of all but the peripheral, distalmost gonad tissue. Conversely, Hesp et al. (2002) observed that Philometra sp. (reported as $P$. lateolabracis) infecting Glaucosoma hebraicum had no discernable deleterious cytological effects. Our findings are qualitatively most similar to those of Hine \& Anderson (1981) and Clarke et al. (2006), although these authors found damage in a far greater portion of gonad tissue in the hosts than we did for red drum.

Other authors have differentiated between the host response to dead gonad-infecting philometrids and that to living worms (e.g. Sakaguchi et al. 1987, Oliva et al. 1992, Hesp et al. 2002, Clarke et al. 2006), and while our findings are generally consistent with theirs, a detailed discussion of the immunological elimination of philometrids from fish gonads is wanting. Whether gonad-infecting species of Philometra are inevitably killed by the host or are eliminated after natural senescence or rupture for larval release is not clear, although we and some other authors (Hine \& Anderson 1981, Hesp et al. 2002, Clarke et al. 2006) have reported thick encapsulations around female nematodes that still contained live larvae. In the present study, we interpret the 3-layered granuloma to represent an outside-in progression of host cells surrounding and eliminating nematode tissue. Necrotic foci in the innermost layer appeared to be nematode remains in earlier stages of breakdown than those engulfed by giant cells in the outermost layer, which were presumably in the final stages of elimination. Likely, the granulomatous mass compacts over time and may be passed or otherwise eliminated before the subsequent spawning season. This is the first report of bacterial colonies associated with dead philometrids, and while multinucleate giant cells have been reported associated with gonadinfecting philometrids (Hine \& Anderson 1981), this is the first time that their apparent role, specifically in late-stage elimination of philometrid remains, has been proposed.

Table 1. Comparison of specific histopathological findings from this and previous studies describing teleost host response to both living and fully encapsulated gonad-infecting philometrid nematodes. Previously published sources: (1) Ramachandran (1975), (2) Hine \& Anderson (1981), (3) Oliva et al. (1992), (4) Hesp et al. (2002), (5) Clarke et al. (2006), (6) Perez et al. (2009)

\begin{tabular}{|c|c|c|c|c|c|c|c|}
\hline \multirow[t]{2}{*}{ Observation } & \multirow{2}{*}{$\begin{array}{l}\text { Present } \\
\text { study }\end{array}$} & \multirow[b]{2}{*}{$(1)$} & \multicolumn{4}{|c|}{ Previously published sources } & \multirow[b]{2}{*}{$(6)$} \\
\hline & & & $(2)$ & (3) & $(4)$ & $(5)$ & \\
\hline \multicolumn{8}{|l|}{ Living nematodes } \\
\hline Thickening of stromal connective tissue & $\mathrm{X}$ & & & & & $\mathrm{X}$ & \\
\hline Oocyte maturation halted & $\mathrm{X}$ & & & & & & \\
\hline Necrotic oocytes & $\mathrm{X}$ & $\mathrm{X}$ & & & & $\mathrm{X}$ & \\
\hline Langhans-type giant cells & $\mathrm{X}$ & & & & & & \\
\hline Foreign body-type giant cells & $\mathrm{X}$ & & & & & & \\
\hline Hemorrhage & $\mathrm{X}$ & $\mathrm{X}$ & & & & $\mathrm{X}$ & \\
\hline Oocytes displaced & $\mathrm{X}$ & $\mathrm{X}$ & & & & $\mathrm{X}$ & $\mathrm{X}$ \\
\hline Necrosis of follicles & & & & & & $\mathrm{X}$ & $\mathrm{X}$ \\
\hline Leucocytic infiltrates (general) & $\mathrm{X}$ & $\mathrm{X}$ & $\mathrm{X}$ & $\mathrm{X}$ & & $\mathrm{X}$ & \\
\hline - Macrophages & $\mathrm{X}$ & & $\mathrm{X}$ & & & & \\
\hline - Lymphocytes & $\mathrm{X}$ & & & & & $\mathrm{X}$ & \\
\hline - Eosinophilic granulocytes & $\mathrm{X}$ & $\mathrm{X}$ & $\mathrm{X}$ & & & & \\
\hline - Fibrocytes & $\mathrm{X}$ & & $\mathrm{X}$ & & & & \\
\hline Host blood in nematode gut & $\mathrm{X}$ & $\mathrm{X}$ & & & $\mathrm{X}$ & $\mathrm{X}$ & $\mathrm{X}$ \\
\hline Edema in mesovarian mesentery/perifollicular spaces & $\mathrm{X}$ & & & & & $\mathrm{X}$ & \\
\hline Pyknosis and cellular swelling & & & & & & $\mathrm{X}$ & \\
\hline \multicolumn{8}{|l|}{ Dead or dying nematodes } \\
\hline Necrotic nematode foci & $\mathrm{X}$ & & $\mathrm{X}$ & & & & \\
\hline Polylaminate capsule & $\mathrm{X}$ & & & & & $\mathrm{X}$ & \\
\hline Macrophages & $\mathrm{X}$ & & $\mathrm{X}$ & & & & \\
\hline Lymphocytes & $\mathrm{X}$ & & $\mathrm{X}$ & & & & \\
\hline Eosinophilic granulocytes & $\mathrm{X}$ & & $\mathrm{X}$ & & & & \\
\hline Fibrocytes or fibrotic encapsulation & $\mathrm{X}$ & & $\mathrm{X}$ & & $\mathrm{X}$ & $\mathrm{X}$ & \\
\hline Epithelioid cells & $\mathrm{X}$ & & & & & & \\
\hline Langhans-type giant cells & $\mathrm{X}$ & & $\mathrm{X}$ & & & & \\
\hline Colonies of rod-shaped bacteria & $\mathrm{X}$ & & & & & & \\
\hline
\end{tabular}


Even assuming that postmortem cytological artifacts are avoided (see Nieland \& Wilson 1995 for discussion of the effects of improper fixation in sections of red drum ovaries), one must carefully consider that some lesions may represent normal processes inherent to the progression of spawning. Our observation of minor leucocytic infiltrates in gonadal tissue of both uninfected red drum and from unaffected areas of parasitized ovaries is not unprecedented. Overstreet (1983) reported leucocytic infiltrates associated with the end of the spawning season in red drum. He also noted bacterial colonies associated with atretic oocytes and multinucleate giant cells in spent testes. Many indicators of host response to parasites in ovaries are probably distinguishable from normal resorption processes only by context and degree of severity.

\section{Impacts on health and reproductive potential}

Given the apparent damage Philometra floridensis causes to ovarian tissue, it may be assumed to significantly reduce reproductive output of red drum, but we did not detect this. Ovarian tissue in proximity to nematodes is apparently rendered nonfunctional, at least temporarily, and blood feeding by the female parasites clearly must divert resources from the host's normal metabolic processes. Conversely, the pathological effects of infection appear to be localized, and infected hosts apparently retain good health and substantial reproductive capacity relative to uninfected fish: higher, rather than lower, $K$ was associated with infection. Although our methods did not allow us to evaluate egg quality, this should also be considered in future studies.

This report represents the first published attempt to determine the effects of a gonad-infecting species of Philometra on host reproduction with sufficient sample size and application of methods broadly accepted by fisheries biologists to directly measure fecundity and statistically analyze results. Infection was associated with higher BF even when we accounted for the parasite's tendency to infect larger hosts, but to interpret this relationship as evidence of nematode-driven enhancement of the host's reproductive output would probably be an error. Infected hosts may be able to shift reproductive resources by hydrating more eggs in unaffected regions of the ovary, the same regions in which we deliberately sampled the tissue used to obtain our BF estimates. A similar shift of reproductive resources was demonstrated for coho salmon Oncorhynchus kisutch after unilateral ovariectomy (Luckenbach et al. 2008).
Based on our histopathological findings, we can assume that deliberate sampling of regions containing large nematode bundles would have forced very different results. A host strategy of intraovarian resource shifting could be adaptive, especially if $P$. floridensis infections are seasonally lost, allowing a host's utilization of affected regions in subsequent spawning seasons. In any case, future studies seeking to meaningfully quantify the effects of this parasite on its host's fecundity should take into account the localized nature of nematode pathogenicity.

Questions remain regarding how Philometra floridensis affects reproduction in its host at the organismic and population levels, and about its potential to negatively impact captive red drum in an aquaculture setting. A means of meaningfully and quantifiably measuring the effects of philometrid nematodes on host fecundity must account for the localized nature of pathological changes in gonad tissue, and investigation of parasite effects on egg quality should be considered. Given the importance of the red drum fishery and the use of this species in aquaculture, further studies elucidating the life cycle of $P$. floridensis are warranted. Identification of intermediate and paratenic hosts, and analyses of prevalence and intensity across seasons are worthwhile areas of investigation.

Acknowledgements. Red drum gonads were provided by the FWC-FWRI Fisheries Independent Monitoring Program (FIM), workers of which also collected otoliths and shared fish length and weight data. D. Adams (FIM) provided archival tissue from red drum collected in the Indian River Lagoon. J. Bickford processed gonadal tissues, and M. Singer obtained BF measurements. J. Tunnel, J. Carroll, A. Amick, and L. Crabtree processed and read otoliths to obtain fish ages. C. Young provided information on husbandry practices and collection dates for brood stock at the FWC-FWRI Stock Enhancement Research Facility. A. Richardson, T. Cody, and M. Tabuchi helped to process ovarian tissues for parasitological evaluation, as did S. Hilber, who, along with N. Perry and T. Piacenza, processed samples for histological evaluation. A. Collins, J. Landsberg, E. Leone, and B. Muller provided valuable feedback on early manuscript drafts and statistical analyses. We thank all of the above. Fish collection for this study was funded by grant NA05NMF4331078 to the Florida Fish and Wildlife Conservation Commission from the National Oceanic and Atmospheric Administration (NOAA), USA. Fish life history data collection, tissue processing, and parasitological evaluation were funded in part by State of Florida saltwater recreational fishing license revenues, by the US Fish and Wildlife Service Sport Fish Restoration Grant Programs F-43 and F72, and by Mexico Sabbatical Grant 2007-81 886. The statements, findings, conclusions, and recommendations are those of the authors and do not necessarily reflect the views of the US Fish and Wildlife Service, NOAA or US Department of Commerce. 


\section{LITERATURE CITED}

Brown-Peterson NJ, Wyanski DM, Saborido-Rey F, Macewicz BJ, Lowerre-Barbieri SK (2011) A standardized terminology for describing reproductive development in fishes. Mar Coast Fish 3:52-70

Chávez RA, Oliva ME (2011) Philometra chilensis [sic] (Nematoda, Philometridae) affects the fecundity of the red cusk-eel, Genypterus chilensis (Guichenot) (Pisces, Ophidiidae) in Chile. Acta Parasitol 56:236-237

Clarke LM, Dove ADM, Conover DO (2006) Prevalence, intensity, and effect of a nematode (Philometra saltatrix) in the ovaries of bluefish (Pomatomus saltatrix). Fish Bull 104:118-124

Cook RR, Auster PJ (2007) A bioregional classification of the continental shelf of northeastern North America for conservation analysis and planning based on representation. Marine Sanctuaries Conservation Series NMSP-07-03. US Department of Commerce, National Oceanic and Atmospheric Administration, National Marine Sanctuary Program, Silver Spring, MD

de Buron I, Roumillat WA (2010) Histopathology of two philometrid parasites of the southern flounder, Paralichthys lethostigma. J Wildl Dis 46:277-282

FAO (Food and Agriculture Organization of the United Nations) (2013) Aquaculture topics and activities. Aquaculture. FAO Fisheries and Aquaculture Department, www.fao.org/fishery/aquaculture/en (accessed 22 May 2013)

Frantová D, Bruňanská M, Fagerholm HP, Kihlström M (2005) Ultrastructure of the body wall of female Philometra obturans (Nematoda: Dracunculoidea). Parasitol Res 95:327-332

Franz M, Andrews P (1986) Histology of adult Litomosoides carinii (Nematoda: Filarioidea). Z Parasitenkd 72: 387-395

Franz M, Büttner DW (1983) The fine structure of adult Onchocerca volvulus IV. The hypodermal chords of the female worm. Tropenmed Parasitol 34:122-128

Franz M, Melles J, Büttner DW (1984) Electron microscope study of the body wall and the gut of adult Loa loa. Z Parasitenkd 70:525-536

Franz M, Schulz-Key H, Copeman DB (1987) Electronmicroscopic observations on the female worms of six Onchocerca species from cattle and red deer. Parasitol Res 74:73-83

Froese R, Pauly D (eds) (2013) FishBase. www.fishbase.org (accessed 11 June 2013)

Hesp SA, Hobbs RP, Potter IC (2002) Infection of the gonads of Glaucosoma hebraicum by the nematode Philometra lateolabracis: occurrence and host response. J Fish Biol 60:663-673

Hine PM, Anderson CD (1981) Diseases of the gonads and kidneys of the New Zealand snapper, Chrysophrys auratus Forster (F. Sparidae). In: Fowler ME (ed) Wildlife diseases of the Pacific basin and other countries. Proc 4th Int Conf Wildl Dis Assoc, Wildlife Disease Association, Sydney, p 166-170

Hunter JR, Macewicz BJ (1985) Measurement of spawning frequency in multiple spawning fishes. In: Lasker R (ed) An egg production method for estimating spawning biomass of pelagic fish: application to the northern anchovy, Engraulis mordax. NOAA Tech Rep 36:79-94

Hunter JR, Lo NCH, Leong RJH (1985) Batch fecundity in multiple spawning fishes. In: Lasker R (ed) An egg pro- duction method for estimating spawning biomass of pelagic fish: application to the northern anchovy, Engraulis mordax. NOAA Tech Rep NMFS 36:67-77

Jenkins KLM, McBride RS (2009) Reproductive biology of wahoo, Acanthocybium solandri, from the Atlantic coast of Florida and the Bahamas. Mar Freshw Res 60:893-897

Lamah T, Franz M, Mehlhorn H, Taraschewski H (1990) Comparaison de Philometra ovata Zeder, 1803 et d'Anguillicola crassus Kuwahara et al. (1974) (Nematodes Dracunculoidea): études en microscopie photonique et électronique á transmisssion. Ann Sci Nat Zool Biol Anim 11:123-133

> Lambert Y, Dutil JD (1997) Can simple condition indices be used to monitor and quantify seasonal changes in the energy reserves of Atlantic cod (Gadus morhua)? Can J Fish Aquat Sci 54:104-112

Leber KM (2004) Marine stock enhancement in the USA: status, trends and needs. In: Leber KM, Kitada S, Blankenship HL, Svåsand T (eds) Stock enhancement and sea ranching developments, pitfalls and opportunities, 2nd edn. Blackwell Scientific Publications, Oxford, p 11-24

Lowerre-Barbieri SK, Barbieri LR (1993) A new method of oocyte separation and preservation for fish reproduction studies. Fish Bull 91:165-170

Lowerre-Barbieri SK, Brown-Peterson NJ, Murua H, Tomkiewicz J, Wyanski DM, Saborido-Rey F (2011) Emerging issues and methodological advances in fisheries reproductive biology. Mar Coast Fish 3:32-51

Luckenbach JA, Kusakabe M, Swanson P, Young G (2008) Unilateral ovariectomy increases egg size and reduces follicular atresia in the semelparous coho salmon, Oncorhynchus kisutch. J Exp Zool 309A:468-476

Moravec F (2006) Dracunculoid and anguillicoloid nematodes parasitic in vertebrates. Academia, Prague

$>$ Moravec F, de Buron I (2009) New data on three gonadinfecting species of Philometra (Nematoda, Philometridae) from estuarine fishes in South Carolina, USA. Acta Parasitol 54:244-252

Moravec F, de Buron I (2013) A synthesis of our current knowledge of philometrid nematodes, a group of increasingly important fish parasites. Folia Parasitol 60: 81-101

> Moravec F, Vidal-Martínez VM, Vargas-Vázquez J, VivasRodríguez C and others (1997) Helminth parasites of Epinephelus morio (Pisces: Serranidae) of the Yucatan peninsula, southeastern Mexico. Folia Parasitol 44: 255-266

> Moravec F, Fajer-Avila EJ, Bakenhaster M (2010) Philometra floridensis sp. n. (Nematoda: Philometridae) from the ovary of red drum Sciaenops ocellatus (Osteichthyes: Sciaenidae) off the coast of Florida, USA. J Helminthol 84:49-54

Moravec F, de Buron I, Measures L (2013) First description of the gravid female of Philometra rubra (Leidy, 1856) (Nematoda: Philometridae), a parasite of the abdominal cavity of temperate basses Morone spp. (Moronidae, Perciformes) in North America. J Parasitol 99:496-500

Murphy MD, Munyandorero J (2009) An assessment of the status of red drum in Florida waters through 2007. IHR 2008-008 Florida Fish and Wildlife Conservation Commission, Florida Fish and Wildlife Research Institute, St. Petersburg, FL

Murphy MD, Taylor RG (1990) Reproduction, growth, and mortality of red drum Sciaenops ocellatus in Florida waters. Fish Bull 88:531-542 
Nieland DL, Wilson CA (1995) Histological abnormalities and bacterial proliferation in red drum and black drum ovaries. Trans Am Fish Soc 124:139-143

Oliva ME, Bórquez AS, Olivares AN (1992) Sexual status of Paralabrax humeralis (Serranidae) and infection by Philometra sp. (Nematoda: Dracunculoidea). J Fish Biol 40:979-980

Overstreet RM (1978) Marine maladies? Worms, germs, and other symbionts from the northern Gulf of Mexico. Mississippi-Alabama Sea Grant Consortium, MASGP-78021, Ocean Springs, MS

Overstreet RM (1983) Aspects of the biology of the red drum, Sciaenops ocellatus, in Mississippi. Gulf Res Rep Suppl 1:45-68

> Perez GR, Roumillat WA, Levesque EM, Connors VA, de Buron I (2009) Synchronization of occurrence of the ovarian philometrid, Philometra carolinensis, with the spawning season of its fish host, the spotted seatrout, Cynoscion nebulosus. Parasitol Res 104:1079-1085

> Peters KM, McMichael RH Jr (1987) Early life history of the red drum Sciaenops ocellatus (Pisces: Sciaenidae), in Tampa Bay, Florida. Estuaries 10:92-107

Editorial responsibility: Sven Klimpel,

Frankfurt, Germany
Quiazon KMA, Yoshinaga T, Ogawa K (2008) Taxonomical study into two new species of Philometra (Nematoda: Philometridae) previously identified as Philometra lateolabracis (Yamaguti, 1935). Folia Parasitol 55:29-41

Ramachandran P (1975) Philometra cephalus sp. n. infecting the gonads of the striped mullet, Mugil cephalus L. from the Arabian coast of Kerala, India, with a note on its pathology. Zool Anz 194:140-144

Sakaguchi S, Yamagata Y, Sako H (1987) Reidentification of Philometra parasitic on the red sea bream. Bull Natl Res Inst Aquac 12:69-72 (in Japanese with English Abstract)

SAS Institute (2006) Base SAS ${ }^{\circledR}$ 9.1.3 procedures guide, 2nd edn, Vol 1-4. SAS Institute, Cary, NC

Séguin G, Bouchard F, Measures LN, Uhland CF, Lair S (2011) Infections with Philometra sp. associated with mortalities in wild-hatched captive-raised striped bass, Morone saxatilis (Walbaum). J Fish Dis 34:475-481

Wallace RA, Selman K (1981) Cellular and dynamic aspects of oocyte growth in teleosts. Am Zool 21:325-343

Wilson CA, Nieland DL (1994) Reproductive biology of red drum, Sciaenops ocellatus, from the neritic waters of the northern Gulf of Mexico. Fish Bull 92:841-850

Submitted: August 26, 2013; Accepted: November 8, 2013 Proofs received from author(s): February 21, 2014 